\title{
Aluísio de Azevedo e o Japão uma apreciação crítica
}

\author{
RENATO ORTIZ
}

\begin{abstract}
RESUMO: Este artigo analisa o livro O Japão, de Aluísio de Azevedo, que foi vice-cônsul do Brasil em Yokohama entre 1987 e 1989. Busca inserir as opiniões do autor e o fascínio que ele parece demonstrar pelo Imperador no contexto complexo do processo de japonização que atravessava o Japão no final dos anos 80 do século passado. Imerso num debate que contrapunha modernização e tradição dentro dos parâmetros de um nacionalismo exaltado, busca-se investigar os fundamentos da visão proposta por um autor marcado pela brasilidade e por uma percepção idílica do isolacionismo nipônico, medida de pureza em relação à Europa. Ressalta-se a oscilação entre um olhar que tende a ver o Oriente como um bloco homogêneo, em contraste com o Ocidente, ao mesmo tempo que coloca em relevo a questão nacional que justamente é a afirmação de uma especificidade.
\end{abstract}

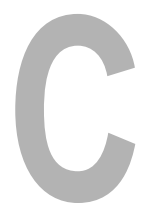

reio que $O$ Japão seja um dos livros menos conhecidos de Aluísio de Azevedo. Eu mesmo só fui encontrá-lo alguns anos atrás quando fazia minhas pesquisas sobre a mundialização da cultura. Consultando uma base de dados francesa deparei-me com uma referência sobre a tese de doutoramento de Luiz Dantas, defendida em Aix-en-Provence em 1980. Há certamente vário motivos que contribuíram para que texto de Azevedo permanecesse na sombra. Os manuscritos jaziam há anos na Academia Brasileira de Letras à espera de que alguém que por eles se interessassem. $\mathrm{O}$ livro acabou sendo publicado em 1984, numa edição patrocinada pela Fundação Japão (Dantas, 1984). Retomo este objeto “antigo" na tentativa de entender como um intelectual brasileiro do século passado se abre para o compreensão de uma sociedade distante. Quais são suas dificuldades, seus fascínios, e por que não, seus equívocos. Aluísio de Azevedo permaneceu no Japão entre 1897
UNITERMOS:

Japão,

modernização, nacionalismo, Oriente/Ocidente, Aluísio de Azevedo.

Professor do Departamento de Sociologia do IFCH-UNICAMP 
e 1899 na função de vice-cônsul em Yokohama. Ele conheceu o país em plena transformação, pois trinta anos haviam se passado desde a Revolução Meiji. $\mathrm{O}$ que lhe seduz dentro deste processo profundo de mudanças? O que lhe desgosta? Escritor realista, ele quer escrever um romance "verdadeiro", pretende penetrar o "coração japonês", desvendar seus segredos recônditos. Ele possuía, é claro, uma experiência acumulada pois havia redigido várias obras sobre a "alma brasileira", sua especificidade mestiça. Não seria a viagem uma ocasião de alargar seu horizonte? Captar a singularidade nipônica, exprimi-la na sua autenticidade, compreendê-la com olhos descomprometidos? Esse foi seu objetivo.

A primeira impressão que se tem de $O$ Japão é um tanto negativa. O “romance", montado em cinco capítulos, é uma visão panorâmica da história japonesa, estendendo-se do período mitológico às vésperas da Revolução Meiji. O autor tropeça, no entanto, num conjunto de erros. Como se o livro tivesse sido escrito com uma certa desatenção. Cito duas passagens: "[Yoritomo - no século XII] assume o posto de comandante em chefe das armas com o título de Bakufu ou Shogun"; "O Japão havia sido descoberto, acidentalmente, pelos portugueses em 1542; São Francisco Xavier, acompanhado de frades agostinianos, dominicanos e franciscanos, tentara desembarcar em 1549 no porto de Kagoshima”. Na primeira citação confunde-se bakufu, o governo militar, com um título, o de xogum; na segunda, outra imprecisão: São Francisco Xavier não viajou em companhia dos prelados das ordens rivais, ele veio apenas com os acólitos jesuítas.

Pode-se considerar essas imprecisões como pecados veniais, porém, outras passagens são mais comprometedoras. Por exemplo, o relato da chegada dos americanos, em meados do século XIX, forçando o Japão a se abrir para o comércio exterior. A presença do Comodoro Perry nas proximidades da costa japonesa é um momento de tensão - a qualquer instante um incidente armado poderia explodir. Como Aluísio de Azevedo retrata este acontecimento? "A imponente esquadra bordejou orgulhosa todo o arquipélago, e foi fundear a leste em frente à barra de Yokohama... Passam-se dias. Os americanos já não pedem, exigem, sob pena de começar o bombardeio, a reposta do memorândum que, em nome do governo da República, enviaram por um oficial de patente superior à 'Sua Majestade o Shogum do Japão'. Marcam afinal um prazo de espera, e no dia precisamente em que terminava esse prazo fatal, Yeçada [o imperador] é encontrado morto, estendido de bruços sobre os degraus do seu trono shogunal... Surge então à ribalta da história contemporânea do Japão a já anunciada figura de Ii Kammon no Kami, príncipe de Hikone... Ora, o sucessor de Yeçada, como já disse, era uma criança de doze anos, e o príncipe de Hikone trata logo de assumir a regência do shogunato... sem se preocupar absolutamente com a opinião do Micado, nem com a da nobreza, e ainda menos com a do povo, recebe em audiência privada o próprio Comodoro Perry, que o toma pelo verdadeiro imperador do Japão e firma com ele um tratado, não provisório como queria o outro, mas decisivo e cedendo mais do que 
ORTIZ, Renato. Aluísio de Azevedo e o Japão: uma apreciação crítica. Tempo Social; Rev. Sociol. USP, S. Paulo, 9(2): 79-95, outubro de 1997.

pretendia o americano, pois além de Chimoda em Izo e Hakodate em Yezo, lhe abriu mão também do porto de Nagasaki ao oeste de Kiuciu”.

Infelizmente a descrição apresentada é inteiramente infundada, sendo fruto de várias confusões. Quando os americanos aportam no Japão (1854), Ii Kammon - uma espécie de vilão para a historiografia oficial japonesa (foi assassinado alguns anos mais tarde por agentes da corrente nativista) - não era ainda regente, e não poderia, pois, ter participado das negociações entre o bakufu e o representante dos Estados Unidos. Ele só assumiu o posto de tairô em 1858, após a morte de Yeçada. Neste momento já não se trata mais de negociar com o Comodoro Perry; vários tratados comerciais já tinham sido firmados (com a Inglaterra e a França) e a abertura oficial dos portos era uma questão de pouco tempo (1859). Outra inconsistência do relato: Yeçada faleceu em 1858 e não em 1854. Portanto, a agonia do imperador diante da iminência dramática de uma situação de guerra, e a traição de Ii Kammon, ao assinar um tratado sem o consentimento da corte são eventos fictícios. Para se perceber essas falhas não é necessário ao leitor ser versado em história. Os comentários e as notas de Luiz Dantas são conscienciosos e detalhados, eles nos esclarecem sobre as imprecisões do autor - troca de nomes, confusão de datas, informações insuficientes, acontecimentos fictícios etc. Fica assim um certo dissabor. A recorrência das incorreções não enfraquece a intenção de se escrever um texto "verdadeiro", "realista"?

Tomo ainda uma outra citação. Descrevendo a mitologia xintoísta, Aluísio de Azevedo afirma: "O espelho de Amateras [deusa do sol] transmitido carinhosamente a seus filhos, representa o símbolo da religião shintoísta, à qual não pode o Micado renegar sem com ela renegar também a qualidade divina de sua própria essência. O shintoísmo é pois no Japão ainda hoje a religião do Estado [grifo meu]". Consultando as notas do comentarista lemos: "Essa afirmação só é aceitável no interior de uma época histórica precisa. Durante o período Meiji, com efeito, e além dele, até o fim da Segunda Guerra Mundial, o 'shintô' representou um papel oficial de religião de Estado". Outro equívoco do autor? Penso que não, e neste caso, eu diria, passamos do terreno da imprecisão para o da versão. É claro que a afirmação "o xintoísmo é ainda hoje uma religião de Estado" é historicamente incorreta. Mas há razões para que Aluísio de Azevedo considere sua validade. O xintoísmo sempre desfrutou no Japão de uma posição ambígua. A rigor, o próprio termo não existia, sendo cunhado tardiamente para dar conta da pré-história japonesa (época anterior a formação do Estado Yamato) ${ }^{1}$. O nome foi dado ao agregado de cultos mágico-religiosos partilhado pelas comunidades tribais que habitavam o Japão. Na verdade, durante um longo lapso de tempo o xintoísmo é uma prática religiosa secundária. Na época aristocrática (séculos VI ao XII) o budismo, trazido da China juntamente com a escrita, torna-se definitivamente a religião da corte. No período Kamakura (século XII ao XIV), ele ganha em legitimidade ao se expandir, sob formas diversas, entre os samurais (zenbudismo), e as classes populares (como religião de salvação) (cf. Kazuo,
1 Até o século VI os japoneses não conheciam a escrita. O Kojiki (712 D.C.) foi o primeiro livro escrito utilizando os ideogramas chineses. Nele encontram-se relatados os mitos fundamentais do xintoísmo (cf. Reischauer, 1970; Hall, 1990). 
1990). O xintoísmo permanece ainda um conjunto heteróclito de crenças periféricas diante do prestígio do neoconfucianismo Tokugawa (1600-1868). Herdeiro do mundo mágico rural, em contraposição à cultura letrada budista e confucionista, ele não produziu escritos nem possuía um clero orgânico e organizado. É apenas no século XIII, após as invasões dos mongóis, que surgem os primeiros textos religiosos. São na verdade falsificações que se pretendem passar por escritos "clássicos", testemunhos de épocas imemoriais (cf. Bary, 1958). Esses livros, tomados como verdadeiros, terão no século XVII uma importância crucial junto à escola do "Aprendizado Nacional". Eles servem de base para a explicitação de toda uma "teoria política" que rejeita a influência estrangeira (chinesa) em favor de uma concepção "autenticamente" nacional. A escola do "Aprendizado Nacional" elabora ainda uma interpretação intelectual consistente, vinculando orgânicamente o xintoísmo à figura do imperador. Contrapondo-o à autoridade do xogum, ela o venera como símbolo da coesão social. Essa ideologia nativista será reativada durante a crise do xogunato no século XIX, e, em 1870, o governo Meiji proclama o xintoísmo religião de Estado. A nova autoridade, moderna e industrializante, encontra assim sua legitimação no pretérito. $\mathrm{O}$ ícone do imperador, descendente da divindade Amateras, torna-se o princípio unificador da nação. Por isso Meiji é visto, pelos historiadores tradicionais, como uma restauração e não como uma revolução. Tudo se passa como se o poder imperial, usurpado pela liderança militar do bakufu, emergisse à tona séculos depois. Íntegro, imaculado, intacto.

Aluísio de Azevedo não se equivoca. Ele partilha uma ilusão coletiva (elaborada minuciosamente pelo Estado moderno e ensinada piedosamente aos adultos e as crianças - a escola primária tem um papel fundamental no processo de inculcação desta ideologia). É isso que nos permite entender seu fascínio pela figura do imperador. Logo no início do livro, após introduzir o mito de Amateras, ele nos apresenta o fundamento do poder imperial: "Assim, o atual imperador, apesar de sua constituição parlamentar, apesar de seu prosaico uniforme de general de divisão, é nada menos do que descendente direto da formosa deusa do sol e tem com certeza na augusta fibrina centelhas das luzes cambiantes do ilustre diadema seu antepassado, sacrossanta procedência donde lhe deriva indiscutível supremacia sobre todos os seus compatriotas terrestres e logo o direito absoluto de ser obedecido... e adorado como divindade que é e como foram todos seus consubstanciais antepassados”. Não há nessas linhas nenhuma ironia. Aceita-se a versão mitológica como razoável.É provável que, para o autor, esse tipo de explicação possuísse uma força de persuasão equivalente a de outras interpretações que conhecia como a de Ś́lvio Romero sobre o "atraso brasileiro" e os ventos alíseos, ou de Nina Rodrigues e a subalternidade da raça negra (cf. Romero, 1960; Rodrigues, 1939). As justificativas forjadas pelos intelectuais brasileiros desta época não eram, como as transmitidas pelo Kojiki, propriamente mitológicas (no sentido estritamente antropológico), mas suas bases especulativas, o clima e a raça, 
eram tão implausíveis como os espíritos dos kami. No fundo, todo esse exercício discursivo, de brasileiros e de japoneses, possuía uma finalidade comum: dar conta, de maneira convincente, isto é, ideológica, da questão nacional. Aluísio de Azevedo preza a figura imperial porque ela reforça a totalidade nacional: sua eficácia simbólica, eu diria em termos durkheimianos, gera uma solidariedade mecânica entre os membros de um povo fragmentado pela ameaça estrangeira. Yeçada ganha então uma dimensão desproporcional. Basta reproduzir seu diálogo com o xogum no momento em que a exigência da abertura dos portos se impõe:

- É preciso varrê-los! exclamou sinteticamente o Monarca.

- O melhor, insistiu o outro, seria aceitar uma conferência com Perry....

- Isso é um paliativo que a ninguém aproveita!

- Mas que ganha tempo, durante o qual nos prepararíamos para a resistência e para a vitória neste momento implausíveis.

- Não engoliriam semelhante isca!

- Os ocidentais não conhecem absolutamente o mecanismo político do Japão... nem sequer sabem ao certo qual é o verdadeiro chefe de Estado; seria fácil por conseguinte engodá-los durante muito tempo.

- Mas cedendo sempre!

- Cedendo sombras de concessões... Que pode valer um simulacro de tratado, sem a assinatura do Imperador.

- Um tratado? Nunca! É preciso varrê-los! Se o shogun, que é o Comandante das Forças, desobedecendo as minhas ordens, não der quanto antes providências para repelir os bárbaros, eu próprio chamarei às armas os príncipes japoneses e irei em pessoa comandá-los.

Há algo de melodramático nesta conversa imaginária. Mas não é isso que importa. A assinatura dos tratados desiguais foi de fato um elemento decisivo no enfraquecimento político do xogunato. Entre 1840-1868 o país vive uma crise constante, suas fronteiras sendo ameaçadas pela presença estrangeira. Os russos se apoderam das ilhas Sakalina, próximas de Hokkaido, ao norte de Honshu e Shikoku, os ingleses derrotam os chineses na guerra do ópio (1842-1843), e os americanos, com a conquista do oeste, querem abrir uma rota marítima na direção do Pacífico (cf. Bolitho, 1989). A chegada do Comodoro Perry cristaliza esse conjunto de tensões. Entretanto, em nenhum momento o imperador é parte ativa deste confronto. Seu papel político é inexistente. $\mathrm{O}$ governo Tokugawa estava montado numa estrutura que excluía a intervenção da corte (cf. Totman, 1988). A leitura de Aluísio de Azevedo 
sugere a existência de um monarca que faz, diz, comanda. Ele admoesta o xogum, exige a retirada dos "bárbaros", se arvora até mesmo em comandante dos exércitos feudais. O entusiasmo é tanto que se chega a imaginá-lo como chefe de uma corrente de opinião. "Foi desse modo que se formou, para logo desenvolver maravilhosamente, o partido popular do Imperador, coisa que até aí nunca tinha existido no movimento político". E em outra passagem: "A nação dividiu-se em dois partidos; um pequeno e tímido, outro enorme e forte; o dos curiosos, dos comodistas ou medrosos, que eram pela admissão dos estrangeiros, e o dos nativistas radicais, que clamavam energicamente a favor da repulsão pelas armas. Este último partido compreendia a nação quase inteira".

O ardor nacionalista faz com que se traduza os acontecimentos de maneira oblíqua. Na verdade, o movimento nativista nunca assumiu um caráter popular. A tradição kokugaku, elaborada pela escola do "Aprendizado Nacional" nos séculos anteriores, galvaniza apenas alguns grupos de samurais, geralmente provenientes de estratos sociais mais baixos. Ao afirmar a supremacia do imperador diante do xogum, eles não querem conspirar contra seus senhores, mas apenas corrigir uma situação política que consideram insustentável. As lutas sociais no Japão se inserem dentro do quadro rígido de uma sociedade estamental. A Revolução Meiji é o resultado da mobilização de parte da elite japonesa e não das classes populares, ou de um conjunto de pessoas socialmente desclassificadas. Arigor, a separação entre camponeses e samurais impede qualquer comunicação mais profunda entre eles. As revoltas populares desta época nada tem a ver com a questão nacional. Trata-se de movimentos contra a deterioração da vida, principalmente durante os anos 30 e 40, quando o Japão passa por um período de colheitas difíceis, e a fome se alastra por toda a ilha. A crise política se circunscreve ao universo das elites (cf. Jansen, 1989b). Dentro deste contexto o símbolo do imperador, mas não a sua projeção real, tem um papel relevante. Alguns senhores feudais (das regiões de Satsuma e Choshu) se aproximam da corte e, ao ganhar força, promovem uma guerra civil contra o xogunato. A casa imperial surge assim como base articuladora da luta, mas comandada na prática por grupos insatisfeitos com a família Tokugawa. A nação não se encontra dividida entre "dois partidos" como idealiza Aluísio de Azevedo. O "povo” é excluído deste processo, e a corte não possuía de fato nem exército, nem comando efetivo, embora do ponto de vista ideológico a figura do imperador seja da maior importância. Ela legitima a revolta dando-lhe forma e sentido.

Aluísio de Azevedo participa, portanto, de uma visão elaborada pela historiografia oficial e pela ideologia do sistema imperial. Sua perspectiva associa nação e tradição. Isso não se faz por acaso. Sua estadia no Japão coincide exatamente com o momento em que esta ideologia, embora calcada em premissas anteriores, adquire um grau de coerência e de credibilidade pública [vários autores consideram que isso ocorre em torno de 1890] (cf. Gluck, 1985). Até então, após 1868, tinham sido feitas várias tentativas para 
se reformar o aparato produtivo e administrativo estatal e o Japão conheceu um período no qual imperou a voga das idéias ocidentais (é o caso do ideário liberal e das reformas educacionais de inspiração franco-republicanas). No entanto, no final dos anos 80, ocorre um movimento inverso: a japonização (cf. Nogai, 1971). A fase de experimentos se encerra e a afirmação nacional se faz em torno da unidade do imperador e da valorização da tradição. Os intelectuais japoneses fazem então uma releitura de sua história, interpretada agora segundo as conveniências dos problemas que enfrentam. Neste contexto, já não é mais o tema dos tratados desiguais que interessa, mas o choque das civilizações. A temática modernidade x tradição emerge com toda força. Vamos encontrá-la também em Aluísio de Azevedo. Quando se compara, por exemplo, O Japão a um outro texto seu, Japonesas e norte-americanas (1980). Luiz Dantas, na apresentação do livro, aponta justamente para esse aspecto preocupado com um tipo de leitura nacionalista. Ele adverte o leitor: "Japonesas e norte-americanas é uma apologia da mulher oriental, enquanto exemplo de submissão e de virtudes domésticas tradicionais, em oposição à mulher americana, liberada mas já contaminada pelos mesmos vícios que afetam a sociedade masculina. Ora, a argumentação de Aluísio de Azevedo sobre esse debate é vizinha da que utiliza quando discute o problema da modernização do Japão, em contato com a civilização Ocidental (grosso modo, o assunto dos capítulos 3, 4 e 5). Aluísio de Azevedo é um ferrenho defensor do isolacionismo japonês e se deixa voluntariamente convencer pelos argumentos do nacionalismo exaltado" (Dantas, 1984, p. 17). A aproximação proposta é de fato pertinente. Há um paralelismo entre o tradicionalismo moral e a proposta nacionalista. Cito o autor: "Para a norte-americana, o adultério é uma pândega despida de atavios românticos, é nada mais que um prolongamento dos prazeres da mesa e da copa... E tudo isso por que? Tudo isso só porque a norte-americana tem a pretensão de fazer-se igual ao homem e, principiando a copiar-lhe a liberdade do pensamento, acabou por macaquearlhe também a liberdade dos atos... Pois senhores, com a mulher japonesa, enquanto viver está fechada no anel de ferro da restrita moral em que até hoje viveu... bem longe de querer ser homem, não lhe discute sequer os direitos de superioridade sobre ela, conservando-se perfeitamente satisfeita e feliz no círculo feminil e passivo que lhe traçou a natureza" (Azevedo, 1980, p. 97). Os argumentos falam por si mesmo. A passagem revela uma posição misógina e conservadora. Interessa porém sublinhar que este tipo de argumentação é cada vez mais freqüente entre os intelectuais japoneses. Na época em que Aluísio de Azevedo escreve, o país passa por um processo de modernização que não atinge ainda o âmago da vida cultural. A entrada no século XX radicaliza este movimento, a cultura "ocidental" chocando-se diretamente com os modos tradicionais. A "mulher oriental” é desta forma vista como núcleo de preservação dos costumes ancestrais. Por isso, um escritor como Mishima, escrevendo após a Ocupação (1945-1952), considera que o homem japonês, diante da influência da democracia americana, estaria se "feminizando". Sua 
2 Um excelente estudo sobre a transformação do pensamento neoconfucianista durante o período Tokugawa é o de Masao Maruyama (1996). releitura do Hagakure (livro do samurai - cuja versão é do século XVIII) procura no passado o alimento espiritual para a superação da crise da modernidade (cf. Mishima, 1987). A ética samurai, masculina e tradicional, funcionaria assim como antídoto à contaminação externa, estranha ao "coração" e ao "gênio" nipônico.

Fica porém uma dúvida. Em que medida $O$ Japão se identifica ao pensamento ideológico japonês? Ele representa realmente um "nacionalismo exaltado"? Gostaria de explorar um pouco mais esse aspecto e sugerir, como um autor brasileiro, ao se aproximar de um mundo diferente do seu, dele se aproxima e se distancia. Não pretendo negar a dimensão nacionalista de Aluísio de Azevedo. Ela é explícita. Cabe no entanto entender como ela se articula, e de que forma se diferencia da trajetória intelectual japonesa.

Um primeiro ponto salta aos olhos: a relação com a China. Na história japonesa existe uma preocupação constante com este tema incômodo: seria o Japão o prolongamento do império celestial, ou teria ele uma capacidade de absorção e de reelaboração das influências introduzidas de fora? A pergunta impõe a necessidade de se entender o contraste entre o autóctone e $\mathrm{o}$ alienígena. Como o período histórico japonês (isto é, o advento de uma sociedade urbana, de classes, com uma administração centralizada) se faz sob a égide chinesa, a dúvida em relação à existência de um "Ser" japonês colocase deste o início. Os historiadores procuram demonstrar que o Japão sempre possuiu uma centralidade própria, sendo portanto capaz de reorientar os valores e as contribuições vindas de outros povos. Foi desta forma que os ideogramas chineses se transformaram no silabário kana, e que o budismo se japonizou junto as classes populares. $\mathrm{O}$ mesmo pode ser dito em relação ao confucionismo. Ele terá no Japão um destino distinto adaptando-se aos imperativos de uma sociedade guerreira ${ }^{2}$. Para a corrente nativista esta discussão não é meramente acadêmica, ela se reveste de um valor estratégico. A valorização da mitologia shinto é uma tentativa de transpor as crenças mágico-religiosas para um plano superior ao budismo e ao confucionismo, ambos considerados como traços alheios as raízes japonesa. A China deixa assim de ser considerada como um modelo, para se transformar em problema, algo a ser evitado. Durante os séculos XVII e XVIII, a polêmica sobre a validade dos textos confucionistas e dos ensinamentos dos sábios chineses tinha uma finalidade clara: desvalorizá-los diante da supremacia da sabedoria endógena. Por isso, a guerra sino-japonesa (1894-1895) tem para os japoneses um certo sabor de revanche. Vencê-la foi uma afirmação inequívoca do destino nacional, uma adeus definitivo ao prestígio milenar chinês (cf. Kenne, 1971).

Nada existe no texto de Aluísio de Azevedo que reedite o confronto entre a China e o Japão. A chegada da civilização chinesa é vista como sendo harmoniosa e promissora. "Ela vem espontaneamente favorecer a ação da corrente civilizadora". Com efeito, o autor tem uma grande admiração pelos inventos e pelas técnicas chinesas. No capítulo primeiro, ele enumera uma longa lista de benefícios que advém do contacto cultural: a escrita, a impren- 
ORTIZ, Renato. Aluísio de Azevedo e o Japão: uma apreciação crítica. Tempo Social; Rev. Sociol. USP, S. Paulo, 9(2): 79-95, outubro de 1997.

sa, a bússola, o moinho de pilar arroz, as técnicas de metalurgia, a moeda, o papel, o relógio d'água, as rodas hidráulicas, a tinta nanquim, a seda e a porcelana, as noções de astrologia e o calendário. "Todas essas maravilhas, perfeitas pelos nipons entre o ano 284 e 703 [há um erro nessas datas] da nossa era, só muitos séculos depois foram sabidas e exercidas pela então agreste Europa, onde todavia por tal modo se desenvolveram e apuraram que é agora a cultura ocidental, hoje rematada e extrema, que refluindo, vem civilizar de novo a velha terra do Oriente, de cujo seio abundante Árias nasceu para gerar novas e mais formosas raças". A menção à Europa é sugestiva. Ela possui um duplo significado. Primeiro, Aluísio de Azevedo reconhece o valor das sociedades asiáticas, percebendo como muitas de suas conquistas só bem mais tarde serão conhecidas pelas culturas ocidentais. Ele se afasta assim de uma leitura eurocêntrica da história. Na verdade, qualquer comparação entre o avanço tecnológico do mundo chinês e a evolução material da Europa Medieval é certamente desfavorável para essa última ${ }^{3}$. Apenas uma visão distorcida pode considerar o progresso do mundo ocidental como algo contínuo e ascendente a partir de sua origem greco-romana. Mas há ainda na citação uma outra dimensão que vale a pena realçar. Ao afirmar a originalidade dos povos asiáticos frente a Europa, Aluísio de Azevedo acaba por borrar as diferenças entre a China e o Japão. Os nativistas enfrentavam um dilema, afirmar a identidade japonesa diante da influência estrangeira. O olhar brasileiro é pouco sensível a tais sutilezas. Ele enxerga o oriente em bloco, como se tratasse de uma totalidade coerente e coesa. O contraste Oriente/Ocidente ofusca assim as particularidades existentes entre os povos asiáticas. Para Aluísio de Azevedo, o estrangeiro não é o chinês mas o europeu e o norte-americano. Sua perspectiva mistura um certo romantismo e a crença na existência de um "orientalismo" capaz de impulsionar o pensamento e os costumes numa direção radicalmente diversa do mundo ocidental ${ }^{4}$. $\mathrm{O}$ oriente espelha sua alteridade e não se configura, pois, como algo real e concreto, é abstrato e distante, não possui contradições ou conflitos.

Outro aspecto diz respeito ao período Tokugawa. Antes do século XIX o papel do nativismo é puramente teórico. Trata-se de contestar a idéia de uma moralidade atemporal que, em princípio, teria sido codificada para sempre nos textos clássicos chineses. Ao introduzir a história no processo de interpretação dos acontecimentos, a escola do "Aprendizado Nacional" pode revalorizar o elemento especificamente japonês. O centro da polêmica tornase evidentemente o papel do imperador. Os nativistas, olhando para a sociedade chinesa, dizem que aí várias dinastias se sucederam umas as outras, levando o país a desordem e ao caos. O caso do Japão em princípio seria diferente, pois, desde a época Yamato, o japonês teria praticado uma reverência e uma submissão irrestrita a uma única casa dinástica. Toda a discussão se desloca assim para o plano político. Os nativistas recusam a idéia de um "mandato celeste", maneira pela qual o neoconfucionismo legitimava o poder militar. Segundo ele, isso teria ocorrido por causa da imoralidade e dos excessos
3 Para uma comparação histórica entre a China e a Europa, cf. Fraser (1986).

4 O fascínio dos intelectuais, artistas e estudiosos ocidentais pelo oriente foi trabalhado por diversos autores. Entre eles aponto Maxime Rodinson (1989) e Edward Saïd (1990). 
da corte (os anos anteriores ao século XII), o que se tornou incompatível com os preceitos divinos. A "vontade dos Céus" teria então transferido o poder da corte para o bakufu. O pensamento nativista, ao criticar a "teoria do mandato celeste", introduz uma sutil diferença em relação à legitimação do poder. Ele preserva a dicotomia entre o imperador e o xogum, mas inverte o raciocínio anterior: o imperador é a fonte de legitimidade que investe o bakufu de poder (o que significa dizer: por motivos outros tal investidura poderia ser retirada). Cabe no entanto sublinhar. Apesar das discrepâncias interpretativas, o nativismo não questiona na prática o domínio Tokugawa. Aceita-se sua existência e seu mando. É só no século XIX que as dúvidas teóricas transformam-se em certezas políticas; surge então uma nova palavra-de-ordem "reverência ao imperador e expulsão dos bárbaros". Um autor da época procurando compreender este momento de crise diz o seguinte: "[Com Hideyoshi e Ieyasu - xoguns que derrotaram as forças medievais - houve a unificação do país] Então toda a terra e toda a população ficou sob um controle único, e assim todos, ao obedecer o comando do xogunato, pagavam respeito à benevolência da corte celeste. A paz reinou suprema sobre a nação. Porém, por causa desta paz prolongada apareceram os sinais de fraqueza e de preguiça: os senhores feudais tornaram-se descuidados, não fazem mais provisões para os tempos de necessidade, pessoas desleixadas são deixadas sem punição, bárbaros estrangeiros esperam em nossas costas por uma oportunidade qualquer. Por isso todas as pessoas, das classes alta e baixa, preocupam-se apenas consigo mesmo, com o ganho egoísta, sem se preocupar com a segurança da nação. Essa não é a maneira de se preservar a política nacional. Quando um grande homem assume a liderança ele não se preocupa com a inatividade do povo. Líderes medíocres pensam apenas numa paz fácil e receiam o imobilismo do povo" (Seishisai, 1958, p. 87-88 ). Retenho da passagem não tanto a parte relativa ao exorcismo da ameaça estrangeira (no caso ocidental), mas a crítica que se faz a sociedade Tokugawa. O raciocínio do autor é claro: a ordem social é uma manifestação da vontade "benevolente da corte celeste", ou seja, do imperador. Cabe, porém, ao xogum administrá-la. No início, a pacificação do país é benéfica para todos. Surge entretanto nos últimos anos do domínio Tokugawa um conjunto de problemas. A moralidade dos homens, dirigentes e dirigidos, degrada-se. A longa paz é ameaçada pela mediocridade das autoridades, pela preguiça da população, pela ganância do ganho fácil. É claro que esta explicação de cunho moral é insuficiente. Não obstante, ela revela o profundo mal-estar que se alastra na sociedade japonesa. A estabilidade social e política que havia imperado durante dois séculos dava agora sinais de cansaço (cf. Nakane, 1991). Nas cidades, uma classe de comerciantes enriquecidos tinha cada vez mais proeminência nos negócios e junto as autoridades. $\mathrm{O}$ empobrecimento dos samurais os tornava mais vulneráveis à lógica da usura, levando-os a uma maior dependência dos credores "burgueses". A clássica divisão estamental - samurai, camponês, artesão, comerciante - preconizada pelos preceitos religiosos, começava a se tornar anacrônica. 
Surge ainda no campo uma indústria rural produzindo alimentos e tecidos para o mercado, e não mais como se fazia tradicionalmente, privilegiando-se o cultivo do arroz, até então, símbolo de prestígio e moeda principal da Era Tokugawa. A monetarização da economia avança. Essas mudanças aceleram as contradições sociais. O exercício da autoridade política torna-se problemático e a fragmentação do poder leva os senhores feudais a priorizarem seus interesses próprios, escapando ao controle centralizador do xogunato. Por isso o início do século XIX vê nascer uma série de políticas conservadoras que buscam no passado sua inspiração (cf. Jansen, 1989a). Como na citação mencionada, critica-se o afastamento dos cânones da tradição e prega-se o retorno ao ascetismo dos tempos antigos, uma espécie de consolo moral contra as adversidades do presente.

Ora, a visão de Aluísio de Azevedo é inteiramente outra. Ele acredita que o isolamento do Japão, do fechamento dos portos (1625) à chegada dos americanos, teria preservado na íntegra a organização social Tokugawa. Sem mudanças ou contradições. A expulsão dos pregadores católicos e a redução do comércio com o mundo ocidental, com o confinamento dos navios holandeses numa pequena ilha ao largo do porto de Nagasaki, teriam definitivamente eliminado as más influências exógenas. Cito o autor: "Durante esse largo período de bem-aventurança, as várias tentativas de quebrar o isolamento japonês, empreendidas pelos ingleses, pelos espanhóis e pelos russos, abortaram completamente. A disposição geográfica do terreno e as especiais condições metereológicas do clima e da latitude eram vigilantes cúmplices do Tokugawa no seu apertado código das 'Cem Leis'; eram a melhor garantia da estreita reclusão em que desejavam viver os donos do país, caprichoso arquipélago armado com mais de três mil e oitocentas ilhas perigosas, de costas escudadas por tufões e ciclones infernais. Qual seria o louco aventureiro que entestasse contra tais sinistros para ir lá dentro, em terra firme, dar talvez, por entre homens, com ainda mais duros rochedos e mais ferozes tempestades"? Os acidentes geográficos teriam tido assim um papel determinante neste processo. O clássico argumento geoclimático, senso comum da intelectualidade do século passado, surge como subterfúgio explicativo da especificidade da japonesa. Separada do mundo, ela pode florescer sem nenhuma interferência, desabrochando-se em toda sua plenitude.

Mas que sociedade é essa? Aquela descrita como estando debilitada pela mediocridade dos governantes, permeada pela preguiça e pela ganâncias dos homens? Pelo contrário: "O governo feudal dos daimos era contido pelas sábias e humanas leis de Ieiás... Uma alçada, de imediata confiança do Governo Central, composta de cinco membros e disponde de duzentos agentes de tradicional integridade, tinha a seu cargo a fiscalização da gerência dos principados, e, uma vez por ano, passava em revista todos os oitenta e quatro distritos do Império, recolhendo, uma por uma, as queixas e reclamações do povo". E logo em seguida: "O organismo político do Estado, como a própria economia do povo achavam-se na mais sinérgica integridade de equilíbrio e 
força; nele se não acusava nenhum dos vírus que na Europa perturbaram e destruíram o sistema congênere; não havia questão religiosa; não haviam rivalidades dinásticas em luta, nem reivindicações filosóficas e populares contra o direito divino do Trono ou contra a autonomia civil e militar do Shogum...; a vida era fácil e simples, o país abundante; o clima em geral benigno, os patrões afáveis, o caráter do povo risonho e doce". E para completar este retrato idílico: "O povo pelo seu lado tinha tudo o que lhe desejava o coração ainda simples. As relações sociais e as regalias públicas eram, como as relações e as regalias dos poderes constituídos, metodicamente e pontualmente exercidas e observadas. Enfim - a nação era feliz". Portanto: um mundo harmônico e justo. Sinergicamente as classes sociais, nos seus devidos lugares, trabalhavam para o contentamento do todo, as "sábias" leis neoconfucionistas. Dentro desta perspectiva, o equilíbrio da ordem só poderia ser rompido por alguma força externa. A abertura dos portos seria apenas o prenúncio de um desastre maior: a capitulação diante do mundo ocidental. Aluísio de Azevedo não partilha o otimismo dos dirigentes japoneses. Escrevendo em uma época na qual os esforços de modernização não tinham ainda dado os seus frutos, ele desconfia do destino de um país asiático recém-saído de seu despertar "oriental". Entre a modernidade incerta e a tradição milenar ele não hesita, seu exotismo romântico elege o passado como lugar utópico.

Oriente/Ocidente, tradição/modernidade são pares de oposição presentes ao longo de todo $O$ Japão. Mas em que medida eles expressariam um "nacionalismo exaltado"? Retomo esta expressão mencionada numa passagem anterior. Ela não é utilizada apenas pelo comentarista do livro, vamos reencontrá-la em boa parte da literatura que se ocupa da história japonesa. A partir de 1920, a ascensão do militarismo impulsiona o império japonês para uma esfera de dominação territorial cada vez mais abrangente. Entre 1931e 1945 uma parte considerável do Pacífico está nas mãos do poder nipônico (cf. Reischauer, 1970). Da Birmânia ao sul da China, das ilhas Neerlandesas aos Aleutas, os interesses militares e econômicos se impõem. É somente com a derrota na Segunda Guerra Mundial que o sonho da conquista se dilui. Não se pode ainda esquecer que no final do século XIX e no início do XX o Japão já ensaiava alguns passos na direção do imperialismo (guerra com a Rússia 1904-1905). O incentivo dado à indústria bélica foi certamente uma das maneiras encontradas para se modernizar o país. Os economistas são unânimes em dizer que a fabricação de armamentos cumpre uma dupla função: militar e de catalisador da indústria pesada (Allen, 1980). Por outro lado, a busca de novos mercados, seja como fornecedores de matéria-prima, seja como consumidores de produtos fabricados no Japão, estava na base da política expansionista. Existiam ainda motivações de natureza política. O fim da sociedade feudal desestruturou a vida de um contingente grande de samurais; um grupo de guerreiros profissionais se viu assim marginalizado, despossuído de suas regalias hereditárias. Isso foi uma fonte permanente de afrontamentos ameaçando a estabilidade do governo Meiji [por exemplo, a revolta de Satzuma 
ORTIZ, Renato. Aluísio de Azevedo e o Japão: uma apreciação crítica. Tempo Social; Rev. Sociol. USP, S. Paulo, 9(2): 79-95, outubro de 1997.

- 1877]. A guerra foi uma das soluções encontradas para canalizar esse descontentamento latente.

Resta saber como interpretar esses fatos e articulá-los ao momento em que Aluísio de Azevedo escreve. Um primeiro aspecto se liga à própria literatura que se ocupa do assunto. Haveria uma linha de continuidade entre a "Escola do Aprendizado Nacional", o nativismo do início do século XIX, as invasões durante o período Meiji e o militarismo pós-Primeira Guerra Mundial? Essa maneira de ver as coisas, comum entre vários autores anglo-saxônicos, a meu ver postula uma grau de necessidade histórica que na verdade é convincente apenas quando dela fazemos uma leitura a posteriori. Como se existisse uma teleologia nacional independente da ação dos homens e dos conflitos políticos. Há ainda neste tipo de interpretação um outro inconveniente. Deixa-se justamente de entender o contraponto em relação ao qual o nacionalismo japonês se consituiu, ou seja, o imperialismo das potências ocidentais. A idéia de "nacionalismo exacerbado" pode ser então criticada, como se não existisse uma contrapartida em relação à qual ela se manifestasse. Não se trata de defender a ideologia nacionalista - e ela tem profundas implicações no caso do Japão, inclusive junto a literatura nihonjinron atual $^{5}$-, mas de situar melhor o problema que nos concerne. Sobretudo porque Aluísio de Azevedo escreve após a ocupação da Coréia e a guerra sino-japonesa. Mas seria possível derivar desses fatos o futuro militarista do Japão?

$\mathrm{Na}$ verdade $O$ Japão situa-se deliberadamente no passado. O livro termina alguns anos antes da Revolução Meiji com a incorporação dos japoneses à esfera ocidental. $\mathrm{O}$ embate entre Oriente/Ocidente é portanto permeado por um outro dilema: a questão nacional. Esta é uma preocupação que Aluísio de Azevedo traz de sua reflexão sobre o Brasil. O problema é análogo. Evitar a imitação ("macaqueação") dos costumes estrangeiros e afirmar a especificidade de um "povo". Com uma diferença, porém: o Brasil contava apenas com um futuro incerto. Povo "sem tradição", ou melhor, com um passado que desencanta as elites brasileiras, ele somente ultrapassaria suas limitações no momento em que uma nova amálgama das raças produzisse um tipo mestiço capaz de suplantar os atavismos anteriores. Em relação à incerteza brasileira o Japão surge assim como um contraponto promissor. Composto de uma unidade racial - resultado de "uma lenta e surda elaboração homogênica da raça até conseguir fixar o seu tipo" -, isolado dos contactos externos, ele seria ainda dotado de uma tradição ancestral. A questão nacional se identifica, assim, à reafirmação dos costumes e ao combate as forças exógenas.

A discussão desemboca, portanto, no tema do imperialismo. Assunto indigesto para grande parte da literatura anglo-saxônica que inevitavelmente toma partido das grandes potências [ conivência que se faz de forma aberta ou mitigada, como os escritos de Reischauer, embaixador dos Estados Unidos no Japão durante muitos anos]. Entretanto, é justamente no século XIX que os interesses das potências ocidentais (Inglaterra, Estados Unidos, França) se reorientam no continente asiático. Até então, apesar da expansão do capitalis-
${ }^{5}$ A literatura nihonjinron é centrada no discurso ideológico da identidade nacional. Ela procura a todo custo definir o "Ser" japonês como algo singular, radicalmente distinto do mundo asiático e ocidental (cf. Dale, 1995; Akamatsu, 1993). 
mo comercial uma parte substantiva do mundo asiático ainda se encontrava fora do world-system. A China imperial continuava sendo um território fechado sobre si mesmo, e o Japão, no seu isolamento, restringia os contactos com as metrópoles coloniais. Jean Chesnaux afirma que entre 1820 e1830 as relações entre o Ocidente e o Oriente atingem um nível nitidamente mais baixo do que nos séculos anteriores. No plano comercial há um retrocesso, pois na China as missões inglesas fracassam, e na Indochina a Companhia das Índias Orientais tem pouco êxito em seus empreendimentos (cf. Chesnaux, 1976). Durante o XIX a política expansionista ocidental é, no entanto, redefinida. Impulsionada pela Revolução Industrial, num primeiro momento ela toma a forma do laissez-faire, para depois se transformar em imperialismo, isto é, num tipo de dominação cujos objetivos centrais (econômicos e financeiros) deixam de ser propriamente coloniais. Pode-se dizer que até meados do século o Japão, graças à sua posição periférica, conseguiu permanecer fora da órbita das ambições ocidentais. Isso torna-se impossível a partir de 1840. Com a expansão do "sistema mundial", a colisão de visões de mundo é inevitável. A periferia tinha necessariamente de ser incluída no conjunto das trocas mundiais. A assinatura dos "tratados desiguais" foi apenas o início deste processo de integração subalterna.

Aluísio de Azevedo tem consciência do momento em que vive. Conhecedor do meio diplomático, ele está familiarizado com as versões que os representantes das diversas embaixadas estrangeiras alimentam sobre o Japão. Neste sentido, uma passagem de seu texto é esclarecedora: "Bem sei que os europeus e norte-americanos, naturalmente por decoro, não contam deste modo nos seus livros sobre o Japão os fatos que aqui vou narrando, dizem todos os autores, pelo menos os meus conhecidos, que a revolução existia em estado latente no Império Japonês e que a chegada do Comodoro Perry nada mais fizera do que precipitar-lhe os efeitos. É preciso muita má fé, ou não ter sequer cheirado as crônicas japonesas, para sustentar tamanha falsidade histórica! Nem sei como não afirmam logo que o pobre Japão se achava em viva guerra de extermínio e que eles americanos, lá foram impelidos pelos próprios sentimentos de humanidade". Sabemos que a interpretação de Aluísio de Azevedo é incompleta. Fica clara, porém, em sua proposta de escrever um livro "verdadeiro", a preocupação de se narrar a história de um outro ponto de vista. Mesmo levando em consideração os pontos frágeis de sua fabulação romanesca, permanece um elemento de clarividência e de crítica que não pode ser minimizado. Para Aluísio de Azevedo o universalismo ocidental não é necessariamente benéfico, ele traz em suas entranhas os germes da dominação. Por isso ele considera incompreensível "que essa gente civilizada não tivesse um pouco de consciência ou de escrúpulo em urdir o mal que estava a tramar contra a paz e os direitos desse pobre povo, a quem pediam pazes em nome da filantropia e do amor universal". Para logo acrescentar: "Positivamente tinham os japoneses razão em chamar-lhes bárbaros". Dentro desta perspectiva, a palavra de ordem - "reverenciar o imperador e expulsar os 
bárbaros" - não deve ser vista como uma simples manifestação de um espírito exacerbado. Pelo contrário, trata-se da expressão "do sábio instinto de uma raça que defende a sua hegemonia, a sua originalidade, o seu caráter nacional".

O Japão não é um livro de viagens. Nele o autor não se preocupa em relatar suas experiências cotidianas. Não há nenhuma referência ao momento atual, ao tempo das transformações impostas pela Revolução Meiji. Aluísio de Azevedo parece deliberadamente evitar este período de transição marcado pelas contradições de uma modernidade emergente. Seu olhar está comprometido com uma visão orientalista na qual o "exotismo", o "diverso", o "longínquo" são elementos marcantes. Não se trata apenas de uma inclinação japonista, tendência artística em vigor no final do século XIX - Madame Butterfly de Pucini, decoração de interiores fin de siécle, impressionismo francês. Aluísio de Azevedo faz parte de toda uma gama de autores ocidentais que, desde o Romantismo, percebiam a Ásia e o mundo Árabe como uma espécie de redenção em relação ao Ocidente. O "estranho", o "diferente" são esperanças utópicas que contrastam com o universo insensível e anônimo do industrialismo. O passadoé neste sentido fonte de ensinamento, um lenitivo, uma relíquia espiritual capaz de encantar a petrificação dos sentimentos. No entanto, Aluíso de Azevedo não é apenas um intelectual ocidental. Sua brasilidade o leva numa direção diversa dos escritores franceses, ingleses ou norteamericanos. A questão nacional é a expressão deste afastamento. Se por um lado o orientalismo o aproxima da tradição européia, por outro, os conflitos de um mundo dividido em nações, o distancia da metrópole, do estrangeiro agora já não mais compreendido com os olhos embargados pelo exotismo. $\mathrm{O}$ Japão é certamente um país "estranho", sua história revela o radicalmente outro. No entanto, sua posição subalterna na ordem mundial é semelhante à de um Brasil que o autor conhece tão bem. A noção de estrangeiro/distante é, portanto, ambígua em $O$ Japão. Ora ela se identifica às raízes tradicionais ancestrais, ora aos invasores ocidentais. No primeiro caso predomina uma inclinação romântica, no segundo, os fatores políticos. Aluísio de Azevedo transita entre esses dois pólos, e talvez, sem perceber, encontre espaço para afirmar sua singularidade. Sua imaginação romanesca apreende e distorce, aumenta e reduz, enfocando um objeto longínquo com as lentes de sua territorialidade nacional. 


\section{UNITERMS:}

Japan, modernization, nationalism, Orient/Occident, Aluísio de Azevedo.
ORTIZ, Renato. Aluísio de Azevedo and Japan: a critical appreciation.Tempo Social; Rev. Sociol. USP, S. Paulo, 9(2): 79-95, october 1997.

ABSTRACT: The article analyses the book Japan by Aluísio de Azevedo, who was Brazil's vice-consul in Yokohama, between 1887 and 1889. It tries to insert the author's opinions and the fascination he seems to have for the Emperor in the complex context of japonization-process which ran throughout Japan at the end of the 80ies of the last century. Talking into account that the country of that time is immersed in a debate which opposes modernization to tradition inside the parameters of an exalted nationalism, the aim here is to investigate the fundaments of a perspective suggested by an author characterized by his brasility and by an idyllic perception of Japanese isolationism, a measure of purity in relation to Europe. The analysis emphasizes the oscillation between a look which tends to see the Orient as a homogeneous block contrasting with the Occident as well as the national question, which precisely is the assertion of a specificity.

\section{REFERÊNCIASBIBLIOGRÁFICAS}

Akamatsu, Paul. (1993) Histoire et nihonjinron. In: CobBi, J. (org.). Pratiques et representations sociales des japonais. Paris, Harmattan.

Allen, G.C. (1980) Breve historia economica del Japon moderno. Madrid, Technos.

Azevedo, Aluísio de. (1980) Japonesas e norte-americanas. In: Dimas, Antonio. Aluísio de Azevedo: literatura comparada. São Paulo, Abril. . (1984) O Japão. São Paulo, Roswitha Kempf.

Bary, Wm. Theodore de \& Tsunoda, Ryusaku (eds.). (1958) Sources of Japanese tradition. New York, Columbia University Press.

Beasley, W. G. (1989) The foreign threat and the opening of the ports. In: The Cambridge history of Japan: the nineteenth century. Vol. 5. Cambridge, Cambridge University Press.

Bolitho, Harold. (1989) The tempo crisis. In: The Cambridge history of Japan: the nineteenth century. Vol. 5. Cambridge, Cambridge University Press.

Chesnaux, J. (1976) A Ásia Oriental nos séculos XIX e XX. São Paulo, Pioneira.

DALE, Peter. (1995) The myth of Japanese uniqueness. London, Routledge.

Dantas, Luiz. (1984) Apresentação e comentários. In: Azevedo, Aluísio. $O$ Japão. São Paulo, Roswitha Kempf.

Fraser, J. T. (ed.). (1986) Time, science and society in China. Amherst, The University of Massachusetts Press.

GLuck, Carol. (1985) Japan's modern myths: ideology in the late Meiji period. Princeton, Princeton University Press. 
HALL, J.W. (1990) Japan: from prehistory to modern times. London, Charles Tuttle.

Jansen, Marius. (1989a) Japan in early nineteenth century. In: Bolitho, Harold. The Cambridge history of Japan: the nineteenth century. Vol. 5. Cambridge, Cambridge University Press.

. (1989b) The Meiji Restoration. In: Bolitho, Harold. The Cambridge history of Japan: the nineteenth century. Vol. 5. Cambridge, Cambridge University Press.

KAZuO, Osumi. (1990) Budism in the Kamakura Period. In: Bolitho, Harold. The Cambridge history of Japan: medieval Japan. Vol. 3. Cambridge, Cambridge University Press.

Kenne, Donald. (1971) The Sino-Japanese war of 1894-95 and its cultural effects in Japan. In: SHIVELy, D. (ed.). Tradition and modernization in Japanese culture. New Jersey, Princeton University Press.

Maruyama, Masao. (1996) Essais sur l'histoire de la pensée politique au Japon. Paris, PUF.

Mishima, Yukio. (1987) O Hagakure: ética dos samurais e o Japão moderno. Rio de Janeiro, Rocco.

Nakane, C. \& Shinzaburô, O. (eds.). (1991) Tokugawa Japan. Tokyo, University of Tokyo Press.

NogaI, Michio. (1971) Westernization and Japanization: the early Meiji transformation of education. In: SHIVELY, D.H. (ed.) Tradition and modernization in Japanese culture. Princeton, Princeton University Press.

Reischauer, E.O. (1970) Histoire du Japon et des japonais. Paris, Seuil.

Rodinson, Maxime. (1989) La fascination de l'Islam. Paris, La Découverte.

Rodrigues, Nina. (1939) Collectividades anormaes. Coletânea de artigos publicados nas décadas e 80 e 90 do século passado. Rio Janeiro, Civilização Brasileira.

Romero, Sílvio. (1960) História da literatura brasileira. Tomo 1. $1^{\mathrm{a}}$ edição 1888. Rio de Janeiro, José Olympio.

SAïD, Edward. (1990) Orientalismo. São Paulo, Companhia das Letras.

Seishisai, Aizawa. (1958) 1782-1863. In: Bary, Wm. Theodore de (ed.) \& TsunodA, Ryusaku. Sources of Japanese tradition. Vol. 2. New York, Columbia University Press.

ShIvely, D.H. (1990) The Japanization of Middle Meiji. In (ed.). Tradition and modernization in Japanese culture. Princeton, Princeton University Press.

Totman, Conrad. (1988) Politics in the Tokugawa Bakufu. Berkeley, University of California Press. 